\title{
Designing a set of safety standards for surgical short term medical missions
}

\author{
Kelly Wagner ${ }^{1}$, Steven D Schwaitzberg ${ }^{2 *}$, Zaeem Shah $^{3}$, GaurangJoshi ${ }^{3}$, and Jeansol Kang ${ }^{3}$ \\ ${ }^{1}$ PGY1 General Surgery Resident, Department of Surgery, University of Buffalo School of Medicine, New York, USA \\ ${ }^{2}$ Chairman, Department of Surgery University of Buffalo School of Medicine, New York, USA \\ ${ }^{3}$ Third year medical students, Jacobs School of Medicine and Biomedical Sciences, New York, USA
}

\begin{abstract}
The global burden of surgical disease is on the rise. In underserved areas this need is being increasingly met by surgical short-term medical missions (STMMs). However, access to safe surgical care is still of great concern to global health advocates. We sought to evaluate the current safety practices and outcomes of surgical care being provided by STMMs. We looked at 35 primary research papers from surgical STMMs between 1991-2016 and analyzed their documentation of safety standards and follow up procedures. This led us to two important conclusions: 1 - surgical STMM practices and outcomes are not well documented and 2 - there is a need for standardized safety guidelines when participating in surgical STMMs. Here we introduce an actionable set of international surgical safety standards that we invite all short-term surgeons and groups to utilize as a means of setting a foundation for the practice of safe surgery on mission trips.
\end{abstract}

\section{Introduction}

Estimates suggest that $30 \%$ of the global burden of disease is surgical [1,2]. Currently, low and middle-income countries (LMICs) are riddled with barriers to providing safe and effective surgical interventions at the rates necessary. Resource limitations leave patients without appropriate pre-operative work ups, post-operative care or without intervention altogether $[3,4]$. These same limitations leave countries with strained workforces and insufficient healthcare infrastructures [3,5]. With an estimated 321.5 million inpatient surgeries necessary to meet the global burden of disease [1], it is apparent that LMICs will be in need of surgical assistance and guidance, not only for the health of the people, but also for their economic welfare [6]. One increasingly popular approach to providing aid is surgical short-term medical missions. These STMMs function by inviting surgeons and other volunteers to fund their own mission to a developing country for a short period of time during which they perform surgeries for underserved populations. As it stands there is no international regulating body that governs STMMs, nor has anyone established core guidelines for the safe practice of surgical STMMS [7-10]. Typically "success" in such missions is defined by the number of surgeries performed, what Dupuis boldly termed the "body count method" [11]. And with this as a measure, most surgical STMMs boast remarkable successes. Other reports claim that STMMs do not always provide safe, modern, or effective care and therefore have poorer outcomes $[9,12]$. However, without large volume outcomes analyses, neither success nor failure can truly be claimed.

\section{"Better than the alternative"}

Many believe that without taking full responsibility of the patient, with substandard preoperative evaluation, and with little or no postoperative follow up, we are still providing an option that is better than the alternative [13]. But is that true? As a surgical resident we are taught that learning how to do surgery is straightforward; it's learning when not to do surgery that is the challenge. This same challenge exists for the community of global surgeons as well. It was projected in 2008 that with all the STMMs combined, the annual direct investment from the US alone could exceed USD\$250 million [14]. From an economic perspective, we must ask ourselves what use of these funds is the most effective at bringing safe surgical access to underserved populations worldwide. It has been argued that the cost of these surgical STMMs grossly outweighs the benefit, and that we as surgeons are only seeking an "unjustified feel-good experience," what is sometimes called warm glow giving $[7,15]$. Some suggest that it's cheaper, safer, provides better continuity of care, and overall is a more culturally sensitive approach to simply train and pay local surgeons to do the operations [12]. But as Caldron et al. highlights, the expenditures are discretionary to the mission-goer and therefore the existence of the funds may be dependent of the opportunity for warm glow giving [7]. Perhaps it should not be an entirely economic decision; perhaps we can accept excess in cost with the benefits being for both the patient and the surgeon - a benefit that cannot be quantified. However, we cannot accept this discrepancy at the expense of safety. In order to be certain we are performing the safest surgeries possible, we must follow basic safety standards and scientifically evaluate our outcomes. If we cannot ensure the safest possible surgery, including postoperative follow-up, and monitor our outcomes then we may be committing Welling's first sin of humanitarian medicine: "Leaving a mess behind" [9].

Correspondence to: Steven D Schwaitzberg, Chairman Department of Surgery University of Buffalo School of Medicine, 100 High Street, New York, USA, E-mail: schwaitz@buffalo.edu

Key words: global surgery, outcomes analysis, medical missions, global health, surgical safety

Received: February 04, 2017; Accepted: March 03, 2017; Published: March 06 2017 


\section{Methods}

In order to identify primary research articles for our own metaanalysis we sourced two recently published articles which discussed STMM activity in general: Sykes' Short-term medical service trips: A systematic review of the evidence and Alfa-Wali's Practice, training and safety of laparoscopic surgery in low and middle-income countries $[16,17]$. By accepting their Pubmed search parameters as sufficient to capture all primary research from STMMs we used their References section, $n=143$, as a starting point. In order to keep our analysis specific to independent primary research from surgical STMMs we used the following inclusion and exclusion criteria that left us with a total of 35 independent primary research articles focused on surgical STMMs [18-52].

\section{Inclusion criteria}

1. Short Term Medical Mission Trip less than or equal to 2 months

2. Mission trips which included surgical intervention

3. Mission trips occurring after January 1, 1991

\section{Exclusion criteria}

1. Disaster relief mission trips

Each of the included $(n=35)$ articles were read and a set of fourteen questions was asked and answered with either a "yes" or "no" answer based on the information documented in the article (Table 1). If an assessment question was not discussed in the article it was marked as "no" or "0." Once the information was organized in a table the percentages of researchers documenting and/or performing the specific safety/management standards were calculated and graphed (Figure 1).

\section{Results}

The search and screening process yielded 35 primary research papers reporting on surgical STMMs to LMICs for qualitative analysis [18-52]. Results are categorized based on the papers' descriptions of the procedures followed by each mission.

\section{Demographics}

In this analysis 36 countries were locations of STMMs. Missions were based in lower middle-income (GNI per capita \$1026 - \$4035) and upper middle-income (GNI per capita between $\$ 4036$ and $\$ 12375$ ) countries at approximately the same rate, $37.1 \%$ versus $42.9 \%$ respectively.

\section{Logistics}

Most of the missions (74.3\%) reported bringing necessary supplies and over half (54.3\%) included students, volunteers, and resident physicians in their surgical teams. Only $11.4 \%$ reported using translators to facilitate communication with the native population.

\section{Preoperative}

All (100\%) 35 publications reported at least some form of standard procedure used to screen and evaluate potential patients in the preoperative period, usually by anesthesiologists, surgeons themselves or physicians. Obtaining Informed consent was only documented in only $14.3 \%$ of cases.

\section{Intraoperative}

Approximately half (51.4\%) of the missions detailed intraoperative anesthesia standards used. WHO time out procedures were documented in only $2.9 \%$ of publications. None of the articles discussed whether or

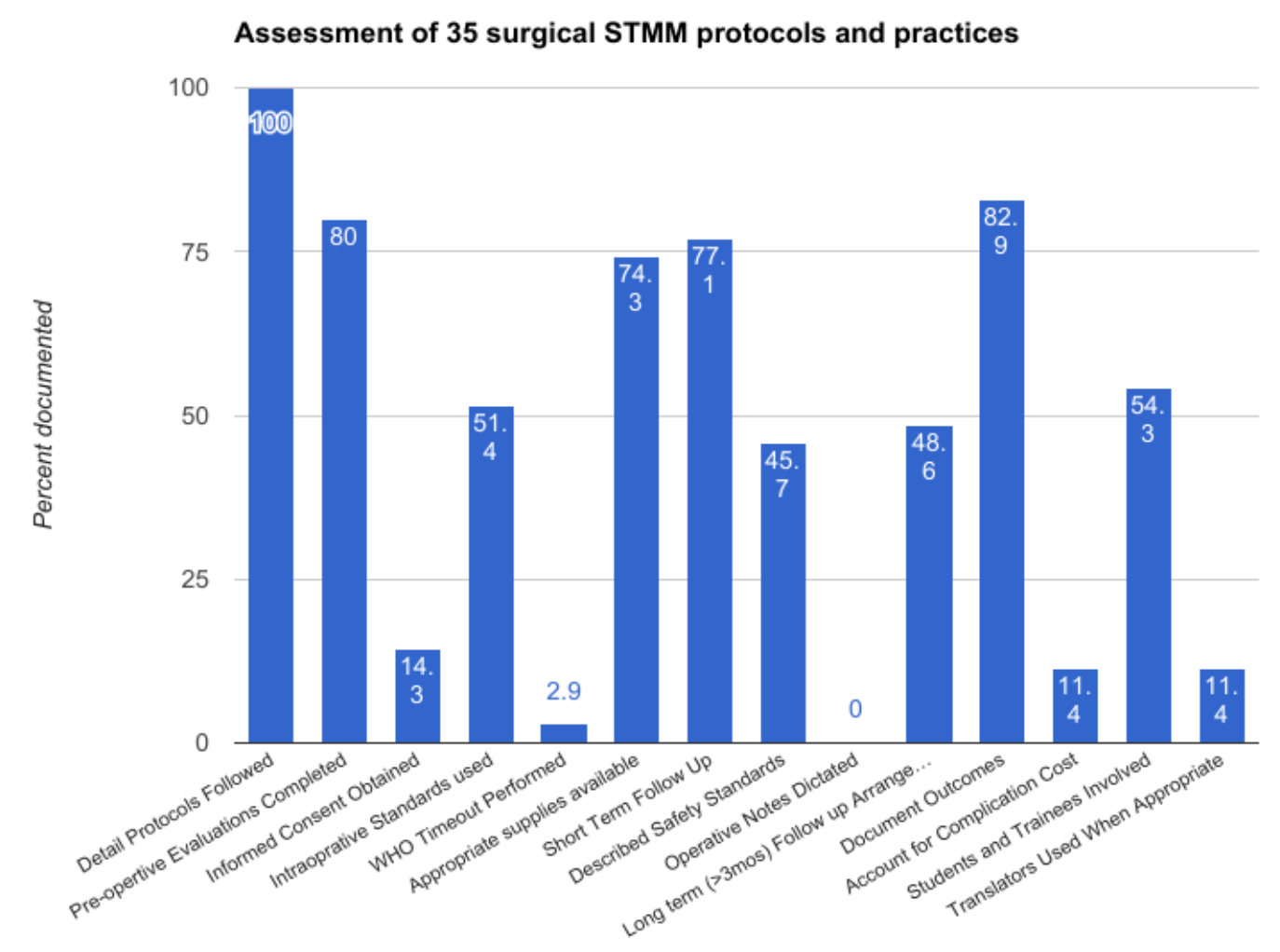

Figure 1.Assessment of 35 surgical STMM protocols and practices. For each of the assessment questions the total number of " $1 \mathrm{~s}$ " were added and divided by the total number of articles assessed to arrive at the percent of researchers documenting their adherence to specific safety standards. 
Table 1. Assessment questions for surgical STMM article analysis. Each article was given an answer of "no" or "yes" which was recorded as a "0" or " 1 " respectively. It is important to note that if a topic was simply not discussed it was coded as "0" or "no."

\begin{tabular}{|l|}
\hline Assessment questions for surgical STMM article analysis \\
\hline Were detailed protocols followed? \\
\hline Did an anesthesiologist see patients preoperatively? \\
\hline Was informed consent obtained? \\
\hline Were intraoperative anesthesia protocols followed? \\
\hline Was a WHO time out performed? \\
\hline Were appropriate supplies brought? \\
\hline Was a short-term follow-up arranged? \\
\hline Were the safety standards used described? \\
\hline Were operative notes dictated/written? \\
\hline Were long-term follow-up arrangements made? \\
\hline Did they document their outcomes? \\
\hline Did they account for funding of complications? \\
\hline Were students and trainees involved? \\
\hline Were translators used when appropriate? \\
\hline
\end{tabular}

not they dictated operative notes, either for the mission's own records or for the local hospital's charting system.

\section{Postoperative}

Most missions (82.9\%) documented the overall outcomes of cases performed by the surgical teams. Over three-quarters (77\%) arranged short-term follow up (1-12 weeks postoperatively), but less than half (48.6\%) had long-term follow up data ( $>3$ months postoperatively).

\section{Discussion}

When conservative estimates put the amount of money spent on STMMs annually at USD $\$ 250$ million, this funding joins the ranks with annual funding for research of AIDS, lung cancer, colon cancer, cervical cancer and the like $[14,53]$. With that in mind, consider the number of papers published on these diseases compared to the number of papers regarding STMMs. Our search for primary research papers pertaining to surgical STMMs over the past 25 years returned less than fifty to evaluate. Even teams who have looked at all STMMs with no restrictions to surgical missions have corralled less than a hundred [16]. We are not documenting enough. There is artistry to surgery, but at its core it is a science and the first step to the scientific method is observation. We must observe what we are doing, and we must observe thoughtfully and critically with a goal of improvement.

\section{How to ensure safe surgical practices}

Surgery is not only the skin-to-skin time. It is much more. Surgery begins with patient selection, and then there is preoperative evaluation and preparation, then intraoperative time, then postoperative follow up and management of complications, and lastly outcomes analysis to guide future practice. To ensure that we are providing safe surgical care to patients on surgical STMMs we must be certain that each of these phases of surgery is accounted for.

\section{Selection, preoperative evaluation and preparation}

It is common practice in STMMs that surgical patients are preselected by local doctors and then the first day of the trip usually entails a clinic day when the visiting surgeons meet with the selected patients to decide whether and which operation will be performed. At this stage the patient also undergoes preoperative evaluation. Of the groups we analyzed all (100\%) reported that patients were evaluated preoperatively. However, one paper describes how the preoperative evaluation consisted of only vitals and a glucometer [54]. Many papers simply did not specify the nature of their evaluations. We suggest that patients should be evaluated preoperatively with the same standards we use in the developed world; if labs or an echo are needed then they should be done. If the environment is without the means, then perhaps the patient would be best served by an alternate plan. This is not to say we should practice the over-testing "CYA" methods that are all too common in the developed world, but rather to only practice medicine, surgery, or anesthesia when we are being as safe as possible. Only five, or $14.3 \%$, of the articles we analyzed discussed having obtained informed consent for surgery. Although obtaining informed consent in a foreign language, with patients who may not be literate, and in a different cultural context presents a variety of complexities, it is still a peremptory aspect of performing surgery $[55,56]$. If we extend the idea of 'preoperative time' to include time leading up to the trip it covers an even wider range of applications. With $54.3 \%$ of trips bringing students and volunteers pre-departure meetings could be arranged to educate and prepare them for their roles on the trip. Some might be taught sterile technique and safe handling of surgical instruments. They could also be taught about the customs and problems of the local population they will be serving. Both sterile technique and cultural competency makes for safer, more patient centered care. For example, in a study of recipients of care from STMMs in the Dominican Republic patients expressed a want for volunteers more familiar with their community, indicating that there is yet a want for increased cultural competency [57].

\section{Intraoperative}

The 2009 WHO Guidelines for Safe Surgery provides an excellent source of detailed intraoperative measures that should be taken to ensure safe surgical practices [58]. Although these guidelines were not specifically designed for surgical STMMs, they are guidelines that have been integrated into safe surgical practices throughout the developed and developing world. As such, they are also guidelines that we encourage traveling surgeons to adhere to, and we include them in our surgical STMM safety standards with emphasis on the WHO pre-incision time out, counting of sponges and instruments, and the need for an operative note [58]. In the developed world we use these guidelines, or some derivative thereof, sometimes begrudgingly, but with every single case. These guidelines were established for the world, for our patients' safety, and with the limitations of austere environments in mind. When we travel as foreign visitors to a developing world to perform surgery, we should continue to adhere to these guidelines in large part because it is the safe thing to do, but also because it gives us an opportunity to demonstrate the ease and efficacy of implementing them to our local colleagues. In our analysis, only one of the 35 papers documented that a WHO time out had been performed. Though nineteen of the 35 (54.3\%) mentioned specific guidelines or standards they were following, none gave any details regarding the standards or deviations from the standards. None of the papers detailed whether or not an operative note was written or the nature of said operative note. In the developed world where these minimum standards are required by law there is an understanding that they are happening and their documentation would be redundant. However, in the world of STMMs, where there is no oversight, no regulating committees, and no courtroom looming in the background, compliance with these safety standards is at risk. Therefore, until such a regulating body exists, we must document that these standards are being met, not because the law requires it, but because evidence and experience tells us it's the right thing to do.

It is important to note that the primary focus of most of these publications was unrelated to reporting mission protocols and 
therefore may not have included specific details, leaving it unclear whether the missions did not perform these tasks or the papers simply failed to describe them.

\section{Postoperative follow-up and complication management}

Some authors have suggested that the burden of follow-up and complication management falls to the local providers [59]. However, it is not reasonable to leave this to local providers without preestablished relationships, and without providing funding. As it is presumed that the patients we serve on surgical STMMs are without the resources to pay for the surgery, it is unreasonable to assume they have the resources to afford any complications. In a bad scenario, the local provider is disenchanted with our 'dumping,' but the patient is managed appropriately. In the worst scenario, the patient does not receive the care $s /$ he needs and our intervention caused more harm than good. This is why Welling labeled humanitarian medical sin number four, "failing to have a follow up plan" [9]. It goes without saying that establishing follow-up plans is by far the most challenging aspect of surgical STMMs, but this does not obviate the need. In the 2009 WHO Guidelines for Safe Surgery they recommend at a minimum the monitoring of wound infection rates, day-of-surgery and thirty-day mortality rates [17]. Since $96 \%$ of surgical site infections occur within 28 days we suggest at minimum one arranged follow-up for all surgical interventions [60]. Of the papers we assessed 77\% of surgical STMMs arranged for a short-term follow-up and $48.5 \%$ arranged for long term follow-up. However, most did not detail the average length of followup, the rate of return, nor did they detail how follow up would occur, and which providers would be responsible for follow up (local versus visiting physicians). Larger surgical mission organizations such as Operation Smile have attempted to create systems for follow-up and themselves found it difficult, reporting only a $\sim 37 \%$ return rate [61]. Although this rate was not ideal, it still provided sufficient information to implement quality improvement measures [61]. Other smaller groups have achieved a $\sim 21 \%$ return rate, which however small, is at least promising in intention [54]. Perhaps the patients did not return because they had no complications, or perhaps they had a complication and had lost trust in the visiting surgeons. Whatever the reasons, there is a large need to find a way to effectively follow patients up. The most successful course probably involves establishing functional relationships with the local doctors. This requires a level of cultural competency and long-term commitment on the side of the non-profits organizing the STMMs. The postoperative follow-up will both serve to provide the best possible care to the patient on whom we have already operated, and it will also allow us to collect and analyze data to improve the care we provide for future patients.

\section{Outcome measures}

Of the papers we analyzed, $\sim 83 \%$ documented outcomes. This is a good sign that those who are writing primary research are documenting outcomes. However, it still stands that the community of surgical STMMs is largely underrepresented in the literature as previously discussed. At the moment, we expect that those surgical STMMs who are not writing papers for publication are using a quantitative rather than qualitative measure of success, the aforementioned "body count method" [11,54]. Small surgical STMM organizations are not exposed to the scrutiny that medical mission moguls such as Operation Smile and Médecins Sans Frontières must face on the international stage [9]. As a result these smaller surgical STMMs may escape the rigmarole of complications. An organization that functions to provide guidelines and guidance to STMMs would be a great asset to empower and promote best practices and quality improvement [7]. Until that body is established, we recommend adhering to our proposed guidelines and documenting adherence as an attestation of patient advocacy.

\section{Recommendations: The International Safety Standards Checklist}

In order to ensure the safe practice of surgery while traveling with surgical STMMs we suggest that surgeons and organizations alike adopt the use of our International Safety Standards for the practice of charitable surgical care (ISS). The standards encompass the care of the patient from the preoperative period through to documenting outcomes. We created a simple tally sheet that can be provided for each patient where boxes are checked to confirm that specific standards were met (Figure 2). At the bottom of the sheet an ISS score is then calculated by adding all of the "yes" answers together, with a total score of 11 possible. A minimum score of 10 is accepted as safe surgery, unless otherwise austere environments prevent the meeting of standards. In this instance an explanation should be documented. By marking and tallying each section on the ISS sheet, surgeons and organizations running surgical STMMs can use this scoring system to voluntarily, and clearly document their adherence to established safety standards. In this way a simple score can be documented (average ISS for all cases) in publications that serves to inform the reader of the level of safety and care taken to ensure proper management of the patient throughout the entire process of surgical intervention.

\section{Preoperative evaluation and testing}

The details of these sections are left to the discretion of the attending surgeon and/or anesthetist, though we do recommend that s/he follow accepted standards of preoperative evaluation.

\section{Consent obtained}

We recommend a standard signed document written in the patient's native language or other culturally appropriate means. If consent were obtained in a non-traditional method it would serve the

\begin{tabular}{|c|c|c|}
\hline \multicolumn{3}{|c|}{ International Safety Standards for the practice of charitable surgical care } \\
\hline & YES & No \\
\hline Preoperatively evaluated & 口 & $\mathbf{\square}$ \\
\hline Preoperative labs/tests/images done & 口 & 口 \\
\hline Informed consent obtained/verified & 口 & 口 \\
\hline Minimum trained staff present & 口 & 口 \\
\hline WHO timeout performed & 口 & $\mathbf{\square}$ \\
\hline Supplies counted & 口 & 口 \\
\hline Operative note dictated & $\mathbf{\square}$ & $\mathbf{\square}$ \\
\hline Patient sent with educational/informational materials & 口 & $\mathbf{\square}$ \\
\hline Patient scheduled for short-term follow up appointment & 口 & 口 \\
\hline Long-term follow-up/complication management arranged & 口 & $\square$ \\
\hline Outcomes documented & 口 & 口 \\
\hline ISS score & & \\
\hline
\end{tabular}

Figure 2. International Safety Standards for the practice of charitable surgical care. Mark each subject with either a "yes" or "no." The ISS score is the total number of "yes" marks. A maximum ISS score of 11 is achievable and a score of 10 is recommended at minimum. 
surgeon/researcher to document this. If the patient is illiterate then we recommend verbal consent with the signature of a witness.

\section{Minimum trained staff}

This includes a trained anesthetist, surgeon, at least one acting surgical assistant trained in sterile technique, and one acting circulator trained in sterile technique. We also recommend all volunteers participate in online or classroom training modules such as those provided by the Stanford University Center for Global Health and the Johns Hopkins University Berman Institute of Bioethics [62].

\section{WHO timeouts, supply counting, and operative notes.}

These standards are excellently detailed in the WHO guidelines for safe surgery and we recommend this is read by all team members not familiar with these protocols [58]. Their nature and constituent parts are well known by any practicing surgeon in the developed world and for the purposes of this article will not be dwelled upon. It is to be noted however that an operative note should be kept for the records of the STMM organization and a copy should be left for the local hospital/ doctors records.

\section{Educational/informational materials}

These should include written and drawn details of important aspects of the patient's surgery and expected postoperative course. It should also include written and drawn details of signs and symptoms that should prompt return to the hospital/clinic. Lastly, it should include any and all relevant information detailing the patient's shortterm and long-term follow up arrangements.

\section{Short/Long-term follow up}

One short-term follow up is recommended at a minimum of four weeks postoperatively so as to assess for wound infection. Ideally, even if a long term follow up appointment is not necessary, the patient should understand (included in the informational materials) how they are to seek assistance in the instance of complication and funds should be allocated to the management of such complications.

\section{Outcomes measurement}

Our proposed guidelines include outcomes measurement as a broad topic. We recommend individualized approaches that cater to each mission, but that includes at a minimum a follow up at or near 30 days postoperatively to assess for wound infection rates and 30-day mortality. When feasible, long-term morbidity and mortality outcomes are strongly recommended to further substantiate the work we do with concrete evidence.

\section{Conclusion}

Although checklists and counts and timeouts can be a laborious part of the operating room flow, they were created and implemented because they reduce the risk of morbidity and mortality, and especially the occurrence of "never events" [63]. Because it is the law, and there are checks and balances, we know that these practices happen in every case in the developed world, making it unnecessary to document their occurrence. But in an environment where no one is watching (except our local colleagues) we cannot assume that basic safety standards are being met unless it is clearly documented. The impetus to adhere to the proposed International Safety Standards and to document participation is simple: the safety of the patient. Let us as surgeons take the initiative to drive the organization and documentation of safety standards, rather than waiting for the iron fist of a regulating body. Let us also chose to document our outcomes, chiefly for the purpose of quality improvement, but also to defend the good work we do with evidence. If we do not, the economists and the nay-sayers will hold audiences captive when they discuss cost-benefits analyses and rare but dramatic complications. We should not see more stories of surgeons to whom it "felt wrong to [perform surgery] knowing that I would very likely perform an operation inferior to what I knew I was capable of" [13]. Moving forward we should create a surgical STMM community of cultural competence, respecting and teaching the local surgeons both directly and indirectly by modeling our values of safety and patient management. Of those surgical STMMs who have documented, their overall safety standards appear to be appropriate, but is it the Hawthorne effect? With so few documenting it is near impossible to surmise the safety protocols of most surgical STMMs. It is well understood that achieving the standards laid out in this paper will be significantly more challenging in the developing world, but let us see this challenge not as an insurmountable burden, but as an opportunity to expand our cultural competency and be innovative in our approaches to bringing surgery and healthcare to a global population.

\section{References}

1. Rose J, Weiser T, Hider P, Wilson L, Gruen R, et al. (2015) Estimated need for surgery worldwide based on prevalence of diseases: a modelling strategy for the WHO Global Health Estimate. Lancet Glob Health 3: S13-S20.

2. Shrime MG, Bickler SW, Alkire BC, Mock C (2015) Global burden of surgical disease: an estimation from the provider perspective. Lancet Glob Health 3 Suppl 2: S8-9. [Crossref]

3. Henry JA, Windapo O, Kushner AL, Groen RS, Nwomeh BC (2012) A survey of surgical capacity in rural southern Nigeria: opportunities for change. World J Surg 36: 2811-2818. [Crossref]

4. Chalya PL, Mchembe MD, Mshana SE (2013) Tuberculous bowel obstruction at a university teaching hospital in Northwestern Tanzania: a surgical experience with 118 cases. World J Emerg Surg 8: 12.

5. O'Hara NN (2015) Is safe surgery possible when resources are scarce? BMJ Qual Saf 24: 432-434. [Crossref]

6. Alkire B, Shrime M, Dare A, Vincent J, Meara J (2015) Global economic consequences of selected surgical diseases: a modelling study. Lancet Glob Health 3: S21-S27.

7. Caldron PH, Impens A, Pavlova M, Groot W (2015) A systematic review of social, economic and diplomatic aspects of short-term medical missions. BMC Health Sevice Research 15:380. Doi 10.1186/s12913-015-0980-3

8. Kingham TP, Price RR, Casey KM, Rogers SO, Kushner Al (2011) Beyond volunteerism: augmenting surgical care in resource-limited settings. Bull Am Coll Surg 96: 16-21.

9. Welling DR, Ryan JM, Burris DG, Rich NM (2010) Seven sins of humanitarian medicine. World J Surg 34: 466-470. [Crossref]

10. Fisher QA, Fisher G (2014) The case for collaboration among humanitarian surgical programs in low resource countries. Anesth Analg 118: 303-309.

11. Dupuis CC (2004) Humanitarian missions in the third world: a polite dissent. Plast Reconstr Surg 113: 433-435. [Crossref]

12. Nthumba Peter M (2010) "Blitz Surgery": Redefining surgical needs, training, and practice in Sub-Saharan Africa. World J Surg 34: 433-437.

13. Bernstein M (2004) Ethical dilemmas encountered while operating and teaching in a developing country. Can J Surg 47: 170-172. [Crossref]

14. Maki J, Qualls M, White B, Kleefield S, Crone R (2008) Health impact assessment and short-term medical missions: A methods study to evaluate quality of care. $B M C$ Health Serv Res 8: 1-8.

15. Crown L (2005) Medical missions: Two views. Paging Dr Schweitzer: a contrarian's viewpoint. Tenn Med 98: 575-576. [Crossref]

16. Sykes KJ (2014) Short-term medical service trips: a systematic review of the evidence. Am J Public Health 104: e38-48. [Crossref] 
17. Alfa-Wali M, Osaghae S (2017) Practice, training and safety of laparoscopic surgery in low and middle-income countries. World J Gastrointest Surg 9: 13-18. [Crossref]

18. Aziz SR, Rhee ST, Redai I (2009) Cleft surgery in rural Bangladesh: reflections and experiences. J Oral Maxillofac Surg 67: 1581-1588. [Crossref]

19. Barrs DM, Muller SP, Worrndell DB, Weidmann EW (2000) Results of a humanitarian otologic and audiologic project performed outside of the United States: lessons learned from the "Oye, Amigos!" project. Otolaryngol Head Neck Surg 123: 722-727.

20. Belyansky I, Williams KB, Gashti M, Heitmiller RF (2011) Surgical relief work in Haiti: a practical resident learning experience. J Surg Educ 68: 213-217. [Crossref]

21. Calisti A, Belay K, Mazzoni G, Fiocca G, Retrosi G, et al. (2011) Promoting major pediatric surgical care in a low-income country: a 4-year experience in Eritrea. World J Surg 35: 760-766.

22. Cheng LH, McColl L, Parker G (2012) Thyroid surgery in the UK and on board the Mercy Ships. Br J Oral Maxillofac Surg 50: 592-596. [Crossref]

23. Green T, Green H, Scandlyn J, Kestler A (2009) Perceptions of short-term medical volunteer work: a qualitative study in Guatemala. Global Health 5: 4. [Crossref]

24. Smith HW, Keen M, Edwards E (1991) Cleft lip and palate surgery in La Ceiba, Honduras. Arch Otolaryngol Head Neck Surg 117: 1356-1359. [Crossref]

25. Suchdev P, Ahrens K, Click E, Macklin L, Evangelista D, et al. (2007) A model for sustainable short-term international medical trips. Ambul Pediatr 7: 317-320. [Crossref]

26. Chen AT, Pedtke A, Kobs JK, Edwards GS Jr, Coughlin RR, et al. (2012) Volunteer orthopedic surgical trips in Nicaragua: a cost-effectiveness evaluation. World J Surg 36: $2802-2808$.

27. Clarke MG, Oppong C, Simmermacher R (2009) The use of sterilised polyester mosquito net mesh for inguinal hernia repair in Ghana. Hernia 13: 155-159.

28. Huijing MA, Marck KW, Combes J (2011) Facial reconstruction in the developing world: a complicated matter. Br J Oral Maxillofac Surg 49: 292-296.

29. Niska RW, Sloand E (2010) Ambulatory medical care in rural Haiti. J Health Care Poor Underserved 21: 70-80. [Crossref]

30. Pham AM, Tollefson TT (2007) Cleft deformities in Zimbabwe, Africa: socioeconomic factors, epidemiology, and surgical reconstruction. Arch Facial Plast Surg 9: 385-391.

31. Ramsey K, Iliyasu Z, Idoko L (2007) Fistula fortnight: innovative partnership brings mass treatment and public awareness towards ending obstetric fistula. Int $J$ Gynaecol Obstet 99: S130-S136.

32. Reeve ME, Groce NE, Persing JA, Magge SN (2004) An international surgical exchange program for children with cleft lip/cleft palate in Manaus, Brazil: patient and family expectations of outcome. J Craniofac Surg 15: 170-174.

33. Gil J, Rodríguez JM, Hernández Q, Gil E, Balsalobre MD, et al. (2012) Do hernia operations in african international cooperation programmes provide good quality? World J Surg 36: 2795-2801. [Crossref]

34. Torchia MT, Schroder LK, Hill BW, Cole PA (2016) A Patient Follow-up Program for Short-Term Surgical Mission Trips to a Developing Country. J Bone Joint Surg Am 98 : 226-232. [Crossref]

35. Sykes KJ, Le PT, Sale KA, Nicklaus PJ (2012) A 7-year review of the safety of tonsillectomy during short-term medical mission trips. Otolaryngol Head Neck Surg 146: 752-756. [Crossref]

36. Tadisina KK, Chopra K, Tangredi J, Thomson JG, Singh DP (2014) Helping Hands: A Cost-Effectiveness Study of a Humanitarian Hand Surgery Mission. Plast Surg Int.

37. Meo G, Andreone D, De Bonis U, Cometto G, Enrico S, et al. (2006) Rural surgery in southern Sudan. World J Surg 30: 495-504. [Crossref]

38. Isaacson G, Melaku A (2016) Results of pediatric tympanoplasty on short-term surgical missions. Laryngoscope 126: 1464-1469. [Crossref]

39. Maine RG, Hoffman WY, Palacios- Martinez JH, Corlew DS, Gregory GA Comparison of fistula rates after palatoplasty for international and local surgeons on surgical missions in Ecuador with rates at a craniofacial center in the United States. Plast Reconstr Surg 129: 319e-326e.
40. Marck R, Huijing M, Vest D, Eshete M, Marck K, et al. (2010) Early outcome of facial reconstructive surgery abroad: a comparative study. Eur J Plast Surg 33: 193-197.

41. Merrell JC, Tien NV, Son NT (2007) Introduction of microsurgery in Vietnam by a charitable organization: a 15-year experience. Plast Reconstr Surg 119: 1267-1273.

42. Moon W, Perry H, Baek RM (2012) Is international volunteer surgery for cleft lip and cleft palate a cost-effective and justifiable intervention? A case study from East Asia. World J Surg 36: 2819-2830.

43. Nwiloh J, Edaigbini S, Danbauchi S, Babaniyi I, Aminu M, et al. (2012) Cardiac surgical experience in northern Nigeria. Cardiovasc J Afr 23: 432-434. [Crossref]

44. Rumstadt B, Klein B, Kirr H, Kaltenbach N, Homenu W, et al. (2008) Thyroid surgery in Burkina Faso, West Africa: experience from a surgical help program. World J Surg 32: 2627-2630. [Crossref]

45. Tefuarani N, Vince J, Hawker R, Nunn G, Lee R, et al. (2007) Operation Open Heart in PNG, 1993-2006. Heart Lung Circ 16: 373-377. [Crossref]

46. Bouman MA, Marck KW, Griep JE, Marck RE, Huijing MA, et al. (2010) Early outcome of noma surgery. J Plast Reconstr Aesthet Surg 63: 2052-2056. [Crossref]

47. Hughes C, Zani S, O’Connell B, Daoud I (2010) International surgery and the University of Connecticut experience: lessons from a short-term surgical mission. Conn Med 74: 157-160. [Crossref]

48. Husain A, Johnson K, Glowacki CA, Osias J, Wheeless CR Jr, et al. (2005) Surgical management of complex obstetric fistula in Eritrea. J Womens Health (Larchmt) 14 839-844. [Crossref]

49. Calis M, Aral AM, Sencan A, Kanbak M, Vargel I, et al. (2016) Humanitarian Activites of Interplast Turkiye: 6 Years of Experience in Uzbekistan for Surgical Treatment of Cleft Patients and Related Secondary Deformities. Ann Plast Surg 77: 494-498.

50. Walk RM, Glaser J, Marmon LM, Donahue TF, Bastien J, Safford SD (2012) Continuing promise 2009-assessment of a recent pediatric surgical humanitarian mission. J Pediatr Surg 47: 652-657.

51. Cousins GR, Obolensky L, McAllen C, Acharya V, Beebeejaun A (2012) The Kenya orthopaedic project: surgical outcomes of a travelling multidisciplinary team. $J$ Bone Joint Surg Br 94: 1591-1594. [Crossref]

52. Navarro CE (2015) CIRPLAST: Cleft Lip and Palate Missions in Peru. J Craniofac Surg 26: 1109-1111. [Crossref]

53. National Cancer Institute (2016) https://www.cancer.gov/about-nci/budget/fact-book/ data/research-funding.

54. Gil J, Rodriguez JM, Hernandez Q (2012) Do hernia operations in African international cooperation programmes provide good quality? World J Surg 36: 2795-2801.

55. Holt GR (2012) Ethical conduct of humanitarian medical missions: I. Informed Consent. Arch Facial Plast Surg 14: 215-217. [Crossref]

56. Cainzos MA, González-Vinagre S (2014) Informed consent in surgery. World J Surg 38: 1587-1593. [Crossref]

57. Decamp M, Enumah S, O’Neill D, Sugarman J ((2014) Perceptions of a short-term medical programme in the Dominican Republic: Voices of care recipients. Glob Public Health 9: 411-425.

58. WHO Guidelines for Safe Surgery: safe surgery saves lives (2009) Geneva, Switzerland. WHO Press.

59. Wall AE (2014) Ethics in global surgery. World J Surg 38: 1574-1580. [Crossref]

60. Weigelt JA, Dryer D, Haley RW (1992) The necessity and efficiency of wound surveillance after discharge. Arch Surg 127: 77-81. [Crossref]

61. Kassum DA, BChir MB, Valji A, Gulyazov S (2003) General surgery in a distric hospital in Tajikistan: clinical impact of a partnership between visiting volunteers and host specialists. Can J Surg 46(5) 335-339

62. Ethical Challenges in SHort-Term Global Health Training (2017) http:/ ethicsandglobalhealth.org/index.shtml.

63. Jones N (2016) Tune-in and Time-out: Toward Surgeon-Led Prevention of "Never" Events. J Patient Saf. [Crossref]

Copyright: $(2017$ Schwaitzberg SD. This is an open-access article distributed under the terms of the Creative Commons Attribution License, which permits unrestricted use, distribution, and reproduction in any medium, provided the original author and source are credited. 